\title{
Paenibacillus dendritiformis sp. nov., proposal for a new pattern-forming species and its localization within a phylogenetic cluster
}

\author{
Marianna Tcherpakov, ${ }^{1}$ Eshel Ben-Jacob² and David L. Gutnick ${ }^{1}$ \\ Author for correspondence: David Gutnick. Tel: +9723640 9834. Fax: +97236425786. \\ e-mail: davidg@post.tau.ac.il
}

Department of Molecular Microbiology and Biotechnology, George S. Wise Faculty of Life Sciences ${ }^{1}$, and School of Physics and Astronomy, Raymond and Beverly Sackler Faculty of Exact Sciences², Tel-Aviv University, Tel-Aviv 69978, Israel

\begin{abstract}
A new strain capable of forming distinctive patterns during colony development was identified by using a combination of phenotypic characterization, fatty acid analysis and analysis of the 16S rRNA gene sequence. The strain formed either a branched, tip-splitting colony morphology (referred to as the T morphotype) or a chiral pattern exhibiting thinner branches with distinctive curling patterns (referred to as the C morphotype). Isolates of the $T$ morphotype exhibited sequence identities greater than $97 \%$ to Paenibacillus thiaminolyticus JCM 7540. Phylogenetic analysis placed the $T$ morphotype within the Paenibacillus cluster on a phylogenetic tree. On the basis of unique colony morphology and distinctive phenotypic characteristics, it is proposed that the pattern-forming isolates should be placed within a new species of Paenibacillus, Paenibacillus dendritiformis sp. nov., the type strain of which is $\mathrm{T}^{168}{ }^{\top}$ (= 30A1').
\end{abstract}

Keywords: Paenibacillus dendritiformis sp. nov., pattern formation, tip-splitting, chiral morphology

\section{INTRODUCTION}

Certain species among the Bacillaceae have been shown to produce a variety of complex patterns during colony development (Ben-Jacob, 1997; Ben-Jacob \& Garick, 1990; Ben-Jacob et al., 1992, 1994, 1995, 1997 , 1998a, b; Fox \& Rossler, 1991; Kanzawa et al., 1995; Matsushita \& Fujikawa, 1990; Matsushita et al., 1995; Matsuyama \& Matsushita, 1993; Matsuyama et al., 1993). Although microbial patterns are often remarkably similar to those observed in abiotic systems, such as snowflake formation or electrodeposition (BenJacob, 1997; Ben-Jacob et al., 1994), the spectrum of shapes and forms of microbial colonies is much larger and more sensitive to changes in conditions. The major difference between the microbial system and abiotic examples stems from the fact that growing organisms modify their environment as they develop cooperatively, excreting various metabolites and signalling molecules, changing the $\mathrm{pH}$, extracting nutrients from the surface substrate and so on. In order to develop working hypotheses regarding the bio-

The EMBL accession number for the 16S rRNA gene sequence of isolate $\mathrm{T}^{\mathrm{T}} 168^{\mathrm{T}}$ is $\mathrm{Y} 16128$. logical processes governing pattern formation, a generic modelling approach has been developed that is based on close inspection of microbial behaviour and includes features related to cell growth, generation time and production of extracellular wetting fluid that allows the cells to move across the very hard agar surface, as well as various types of cell-cell signalling and communication (Ben-Jacob et al., 1994, 1998a, b; Gutnick \& Ben-Jacob, 1998). The term morphotype is employed to describe the pattern-forming capacity of micro-organisms (Fujikawa \& Matsushita, 1989; BenJacob, 1997; Gutnick \& Ben-Jacob, 1998). However, in order to gain a deeper understanding of the biological basis of pattern formation by various morphotypes, it is necessary to define the particular genes involved in pattern formation, their organization and control. This in turn depends on the identification of morphotypes. In this paper, the identification of two such pattern-forming isolates, their location on a phylogenetic tree and their phenotypic characterization are reported.

\section{METHODS}

Bacterial strains and growth conditions. The pattern-forming isolates used in this study were termed T168 ${ }^{\mathrm{T}}$ (tip-splitting 

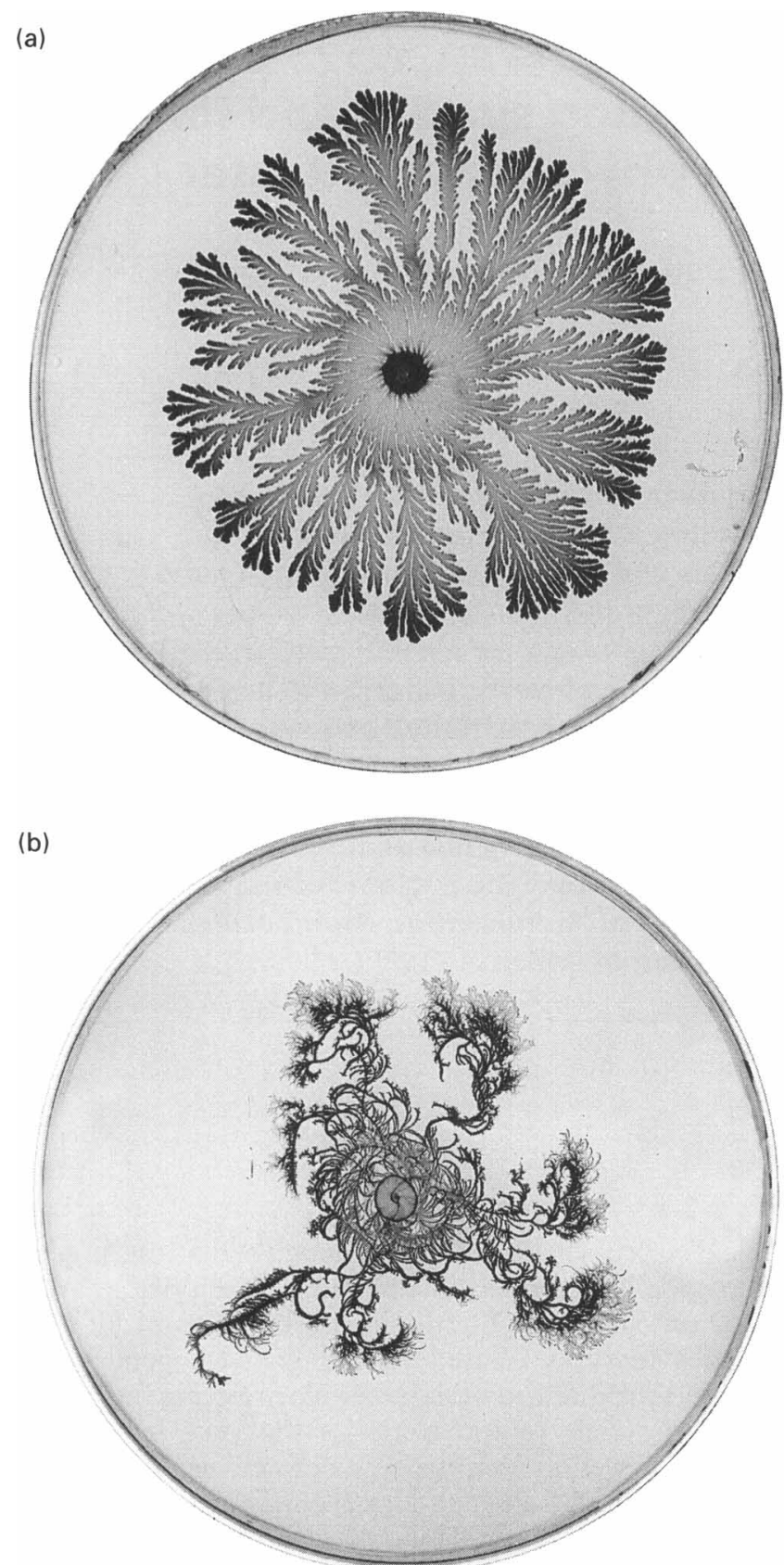

Fig. 1. Representative patterns of (a) isolate $T 168^{\top}$ (tip-splitting) and (b) isolate C168 (chiral). Pattern formation was carried out as described in the text.

morphotype) and C168 (chiral morphotype) (Fig. 1). Both morphotypes were isolated several times in the laboratory of E. Ben-Jacob. When cultures of Bacillus subtilis 168 were spotted on thin agar plates containing $12 \mathrm{ml}$ agar $(1 \cdot 0-1 \cdot 75 \%)$ and peptone broth $(0 \cdot 2 \%)$, the strains routinely grew as compact colonies. Occasionally, at frequencies of about $0 \cdot 1-0 \cdot 01 \%$, bursts of growth exhibiting a new colony morphology emerged. Cells were picked from this new region of growth and restreaked on LB plates several times in order to purify isolates. The T morphotype was isolated on $1.5 \%$ agar and the $\mathrm{C}$ morphotype was isolated on $1 \%$ agar. Bacteria were grown at $37^{\circ} \mathrm{C}$ on LB broth, containing $10 \mathrm{~g}$ bactotryptone, $5 \mathrm{~g}$ yeast extract and $10 \mathrm{~g} \mathrm{NaCl}^{-1}$ distilled water. Working stocks were cultured on LB agar (LB broth solidified with $2.0 \%$ agar) plates (containing about $25 \mathrm{ml}$ medium) for $24 \mathrm{~h}$ at $37^{\circ} \mathrm{C}$. Strains were stored at $4{ }^{\circ} \mathrm{C}$.

Phenotypic characterization. Standard phenotypic characterization (Steel, 1961; Edwards \& Ewing, 1972; Gordon et al., 1973) of isolates $\mathrm{T} 168^{\mathrm{T}}$ and $\mathrm{C} 168$ presented in Table 2 was carried out in part at the ATCC (Manassas, VA, USA). Cellular fatty acid analysis was carried out with the assistance of Analytical Services (Williston, VT, USA) by using high-resolution GC to compare the fatty acid profile of the isolates with a known standard in the database with the MIDI/Hewlett Packard Microbial Identification System.

Pattern formation assay. Pattern formation assays were carried out on thin agar plates containing varying concentrations of agar and peptone broth (Difco) as previously described (Ben-Jacob et al., 1992). Tip-splitting patterns (formed by morphotype $\mathrm{T} 168^{\mathrm{T}}$ ) were typically observed on plates containing $1.5 \%$ agar and $0.2 \%$ peptone. Chiral patterns (formed by morphotype $\mathrm{C} 168$ ) were generally observed on plates containing $0.8-1.2 \%$ agar and $0.2 \%$ peptone. Typically, $12 \mathrm{ml}$ agar-containing medium was added to each plate and dried at room temperature until the initial weight had decreased by $4 \cdot 0-5 \cdot 0 \%$. Overnight cultures of the various strains were grown for $24 \mathrm{~h}$ at $37^{\circ} \mathrm{C}$ in $\mathrm{LB}$ broth and $5 \mu \mathrm{l}$ aliquots were spotted onto the centre of the plate. Plates were incubated at $37^{\circ} \mathrm{C}$. Visualization of the colony morphology was enhanced with Coomassie blue staining as previously described (Ben-Jacob et al., 1992).

Sequencing of $16 \mathrm{~S}$ rRNA genes. Genomic DNA was prepared from $50 \mathrm{ml}$ overnight cultures grown at $37^{\circ} \mathrm{C}$ according to an established protocol (Sambrook et al., 1989). PCR amplification of the 16S rRNA was done as described previously by Di Cello et al. (1997) by using conserved eubacterial sequences from the $5^{\prime}$ and $3^{\prime}$ ends of the $16 \mathrm{~S}$ rRNA gene. The forward primer was $5^{\prime}$ AGAGTTTGATCCTGGCTCAG $3^{\prime}$ and the reverse primer was $5^{\prime}$ TACGGCTACCTTGTTACGACTT 3'. PCR was performed with an Eppendorf Mastercycler 5330 instrument (Eppendorf-Netheler). Amplified 16S rRNA gene fragments were purified with a QIAquick Spin PCR Purification kit (Qiagen) and used as sequencing templates. Sequencing was carried out with an automatic DNA sequencer (ABI Prism 377; Perkin-Elmer).

Comparison of 165 rRNA gene sequences. Sequences determined in this study were compared with 16S rRNA gene sequences obtained from the EMBL, GenBank, DDBJ and PDB databases. Multiple alignment of sequences, calculation of nucleotide substitution rates and construction of a neighbour-joining phylogenetic tree were carried out with the CLUSTAL $\mathrm{W}$ program version 1.6. Alignment gaps and unidentified base positions were not taken into account in the calculations. Sequence identities shown in Table 1 were determined with the BESTFIT program of the GCG package.

\section{RESULTS}

\section{Pattern formation by $\mathrm{T}$ and $\mathrm{C}$ morphotypes}

The distinguishing characteristic of the isolates $T 168^{\mathrm{T}}$ and $\mathrm{C} 168$ is their capacity to form unique, complex 
Table 1. $16 \mathrm{~S}$ rRNA sequence identities to morphotype $\mathrm{T} 168^{\top}$

The 16S rRNA sequence was determined for a PCR-amplified fragment from genomic DNA of strain T168 as described in the text. The 16S rRNA sequence was compared with each of the other sequences by using the BESTFIT program from the GCG package.

\begin{tabular}{|c|c|c|c|}
\hline Species and strain & Accession no. & Identity (\%) & Reference \\
\hline P. thiaminolyticus JCM 7540 & D88513 & $97 \cdot 3$ & Shida et al. (1997a) \\
\hline P. thiaminolyticus JCM $8360^{\mathrm{T}}$ & D78745 & $96 \cdot 6$ & Shida et al. (1997a) \\
\hline$P$. alvei ATCC 6344 & X57304 & $96 \cdot 1$ & Fox \& Rossler (1991) \\
\hline P. apiarius NRRL NRS-1438 & U49247 & $94 \cdot 3$ & Nakamura (1996) \\
\hline P. illinoisensis NRRL NRS-1356 & D85397 & $93 \cdot 5$ & Shida et al. (1997b) \\
\hline P. curdlanolyticus IFO $15724^{\mathrm{T}}$ & D78466 & $93 \cdot 5$ & Shida et al. (1997a) \\
\hline P. kobensis IFO $15729^{\mathrm{T}}$ & D78471 & $93 \cdot 0$ & Shida et al. (1997a) \\
\hline P. larvae ATCC 9545 & X60619 & $91 \cdot 8$ & Ash et al. (1991) \\
\hline Brevibacillus thermoruber DSM7064 & Z26921 & $90 \cdot 1$ & Rainey et al. (1994) \\
\hline Bacillus subtilis NCDO 1769 & X60646 & $89 \cdot 2$ & Ash et al. (1991) \\
\hline Bacillus sp. DSM 8718 & X76442 & $89 \cdot 1$ & Nielsen et al. (1994) \\
\hline Bacillus alcalophilus DSM $1485^{\mathrm{T}}$ & X76436 & $88 \cdot 8$ & Nielsen et al. (1994) \\
\hline Bacillus cereus IAM 12605 & D16266 & $88 \cdot 4$ & Suzuki \& Yamasato (1994) \\
\hline Bacillus coagulans IAM 12463 & D16267 & $87 \cdot 6$ & Suzuki \& Yamasato (1994) \\
\hline Bacillus stearothermophilus $\mathrm{T} 10$ & X57309 & $87 \cdot 5$ & Fox \& Rossler (1991) \\
\hline Bacillus megaterium IAM 13418 & D16273 & $87 \cdot 3$ & Suzuki \& Yamasato (1994) \\
\hline
\end{tabular}

patterns during colony development under specific conditions, determined primarily by the nutrient concentration and hardness of the agar surface. The patterns vary somewhat as these parameters are modified (Ben-Jacob, 1997; Ben-Jacob et al., 1995). The term morphotype has been used to identify the capacity of a strain to form a unique characteristic pattern under particular conditions (Ben-Jacob, 1997; Ben-Jacob et al., 1998a, b; Gutnick \& Ben-Jacob, 1998). When spotted onto the centre of plates containing only a small volume of medium (about $12 \mathrm{ml}$ ), but at agar concentrations greater than about $1.5 \%$, cells of strain $\mathrm{T} 168^{\mathrm{T}}$ swarmed out from the centre to form characteristic branch patterns that exhibit a tipsplitting colony morphology (Fig. 1a). The isolate is thus referred to as T morphotype. After about $48 \mathrm{~h}$ with agar concentrations of about $1.2 \%$ or lower, a burst of new branches from the growing tips is frequently observed. These new growing branches, which are characteristically much thinner, all curl with the same handedness, to yield a chiral morphology, characteristic of $\mathrm{C}$ morphotypes. This chiral morphology is characteristic of isolate $\mathrm{C} 168$, which was isolated from the chiral region of the branched pattern (Ben-Jacob et al., 1995). When respotted onto plates containing the lower agar concentration, the resulting colonies developed with chiral morphology without going through the $48 \mathrm{~h}$ adaptation period (Fig. 1b). Previous results have demonstrated that C168 developed as a result of a morphotype transition from $\mathrm{T}$ to $C$ occurring under specific conditions of lower agar concentration (Gutnick \& Ben-Jacob, 1998).

\section{Identification of the morphotypes}

The complete nucleotide sequence of the 16S rRNA gene from isolate $\mathrm{T} 168^{\mathrm{T}}$ was determined. The highest sequence identities to morphotype $\mathrm{T} 168^{\mathrm{T}}$ are shown in Table 1. Highest identities were found for Paenibacillus thiaminolyticus JCM $7540(97.3 \%)$ and P. thiaminolyticus JCM $8360^{\mathrm{T}}(96.6 \%)$. Other representative strains exhibiting high sequence identities, between 96 and $91.8 \%$, included in order of identity Paenibacillus alvei ATCC 6344, Paenibacillus apiarius NRRL NRS1438, Paenibacillus illinoisensis NRRL NRS-1356 ${ }^{\mathrm{T}}$, Paenibacillus curdlanolyticus IFO $15724^{\mathrm{T}}$, Paenibacillus kobensis IFO $15729^{\mathrm{T}}$ and Paenibacillus larvae ATCC 9545 . In addition, identities ranging from $90 \cdot 1$ to $88.8 \%$ were found for Brevibacillus thermoruber DSM 7064, Bacillus sp. DSM 8718 and Bacillus alcalophilus $1485^{\mathrm{T}}$. In a phylogenetic tree, the $\mathrm{T}$ morphotype was clearly located within the distinct Paenibacillus cluster (Fig. 2) that was reported previously (Shida et al., 1997a).

\section{Phenotypic characterization}

Further evidence supporting the placement of the $T$ morphotype within the genus Paenibacillus emerged from a study of several phenotypic characters (Table 2) as well as analysis of cellular fatty acids (Table 3 ). Cells of strain $\mathrm{T} 168^{\mathrm{T}}$ are motile, Gram-negative rods found either singly or in short chains, with one endospore formed in the subterminal or terminal region of the cell. The colonies on LB agar plates are translucent 


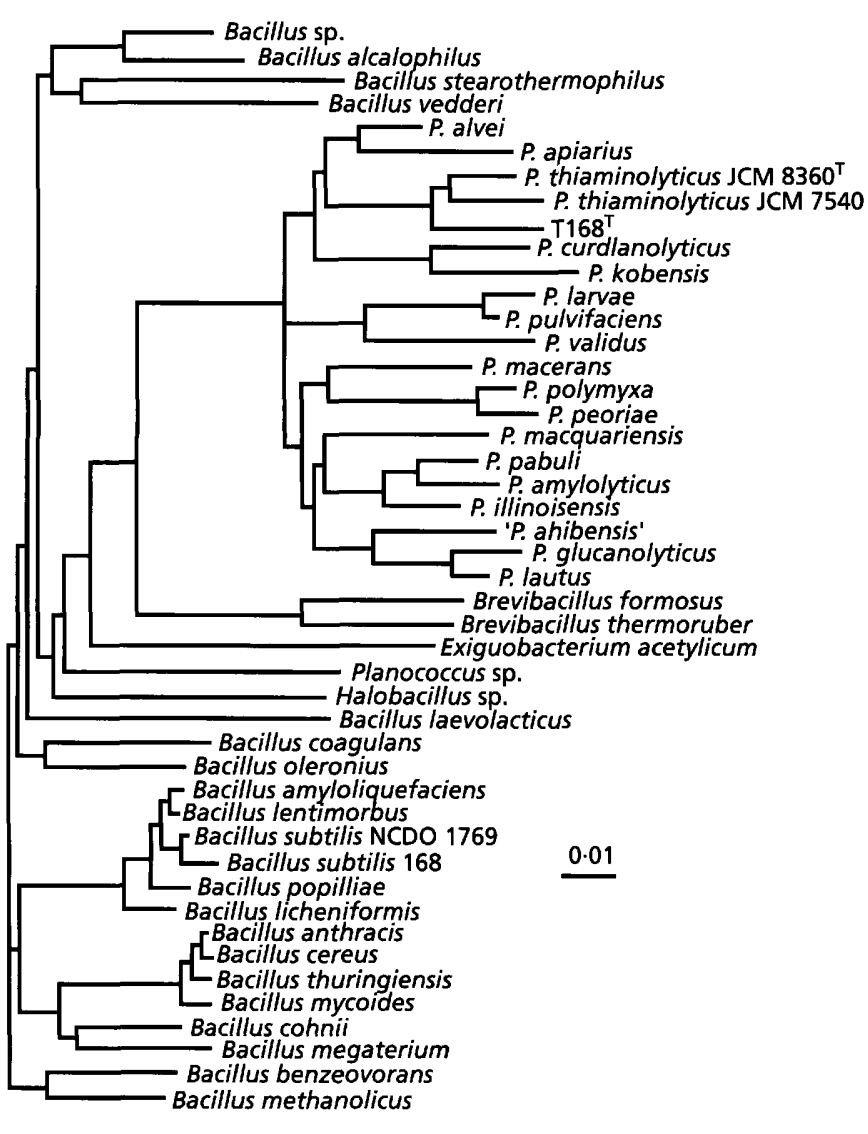

Fig. 2. Phylogenetic relationships of Paenibacillus species and other closely related bacteria based on 165 rDNA gene sequences. The branching pattern was generated by the neighbour-joining method. Bar, 0.01 nucleotide substitutions per site.

and irregular with low convex elevation, a glistening, smooth surface and an entire margin (not shown). Most of the biochemical and nutritional features observed, as well as the $\mathrm{G}+\mathrm{C}$ content, have been reported as characteristic for various species and subspecies of Paenibacillus (Shida et al., 1997a). These characteristics were compared with those reported for $P$. thiaminolyticus, the species showing the highest sequence identity to the T morphotype (Table 2 ). A number of differences were observed (in bold in Table 2). For example, $T 168^{\mathrm{T}}$ was unable to reduce nitrate, decompose tyrosine, use citrate as a carbon source or ferment either mannitol or L-arabinose. In contrast, $P$. thiaminolyticus was reported to exhibit positive reactions for all of these traits with the exception of mannitol and L-arabinose fermentation, which were variable (Shida et al., 1997a). Moreover, the optimum growth temperature for the pattern-forming strain was $37^{\circ} \mathrm{C}$, while that of $P$. thiaminolyticus was $28^{\circ} \mathrm{C}$. Other differences between the closely related Paenibacillus species were found for urea hydrolysis, litmus milk reaction and growth in the presence of $5 \% \mathrm{NaCl}$ (Table 2). The $\mathrm{T}$ morphotype showed clear positive reactions for these features, while $P$. thiaminolyticus was reported to be either negative (urea hydrolysis and litmus milk) or variable $(5 \% \mathrm{NaCl})$. Ignoring the variable behaviour for some of the traits, the morphotype showed the same characteristics as $P$. thiaminolyticus in $74 \%$ ( 23 of 31 ) of the phenotypic tests.

\section{Cellular fatty acid analysis}

The cellular fatty acid composition of the T morphotype is shown in Table 3 and compared with the distribution of fatty acids previously determined for a variety of Bacillus and Paenibacillus strains (Shida et $a l .$, 1997a). The major fatty acid of the T morphotype was found to be the anteiso-branched $C_{15: 0}$, which constituted $43 \%$ of the total. As illustrated in Table 3, this value is within the range previously determined for members of the genus Paenibacillus (Shida et al., 1997a).

\section{DISCUSSION}

In recent years, a number of rod-shaped, endosporeforming strains previously associated with the genus Bacillus have been transferred to the genus Paenibacillus, which was shown by analysis of the 16S rRNA sequences to form a specific monophyletic cluster (Ash et al., 1993; Heyndrickx et al., 1995, 1996a, b; Nakamura, 1996; Shida et al., 1997b). In this regard, phylogenetic analysis of the 16S rRNA sequence from the pattern-forming $\mathrm{T} 168^{\mathrm{T}}$ morphotype placed it within the Paenibacillus cluster. Intracluster identities were greater than $90 \%$ for the pattern-forming strain, which is within the range (between 89.9 and $97.1 \%$ ) previously reported for this cluster (Shida et al., $1997 \mathrm{a}, \mathrm{b})$. It should be noted that no reported $16 \mathrm{~S}$ rRNA sequence from any of the Paenibacillus species showed identities greater than $97.2 \%$ when compared with the 16S rRNA sequences from $\mathrm{T} 168^{\mathrm{T}}$ (see Table 1). In this regard, a putative classification of the $T$ (and C) morphotypes was recently reported (Rudner et al., 1998). In our opinion, these morphotypes were mistakenly classified as members of the genus Bacillus. Moreover, no evidence was presented in that work to justify the placement of the two morphotypes into different species.

Phenotypic characterization of morphotype $\mathrm{T} 168^{\mathrm{T}}$ and cellular fatty acid analysis suggested that the strain is likely to be a member of the genus Paenibacillus and most closely resembles $P$. thiaminolyticus. However, as shown in Table 2 , about $26 \%$ of the phenotypic characters were different for the $\mathrm{T}$ morphotype when compared with the profile for $P$. thiaminolyticus.

It is recommended, therefore, that morphotype T168 ${ }^{\mathrm{T}}$ be placed in a new species within the Paenibacillus cluster. Since the most distinguishing characteristic of the pattern-forming $\mathbf{T}$ morphotype is its branched colony morphology, it is suggested that the new species should be called Paenibacillus dendritiformis sp. nov. 
Table 2. Distinctive phenotypic characters of $T$ morphotype and $P$. thiaminolyticus

Only $\mathrm{T} 168^{\mathrm{T}}$ is shown, as no differences were found between $\mathrm{T} 168^{\mathrm{T}}$ and $\mathrm{C} 168$ for any characters examined. Data for P. thiaminolyticus are from Nakamura (1990) and Shida et al. (1997a). Characters shown in bold differ between $\mathrm{T} 168^{\mathrm{T}}$ and $P$. thiaminolyticus. NT, Not tested; v, variable.

\begin{tabular}{|c|c|c|}
\hline Character & $\mathbf{T 1 6 8}^{\mathrm{T}}$ & P. thiaminolyticus \\
\hline Spore shape & Round, cylindrical or oval & Oval \\
\hline Swollen sporangia & + & + \\
\hline Anaerobic growth & + & + \\
\hline Catalase & + & + \\
\hline Oxidase & + & + \\
\hline Nitrate reduction & - & + \\
\hline \multicolumn{3}{|l|}{ Production of: } \\
\hline Acetylmethylcarbinol & - & - \\
\hline Indole & + & + \\
\hline Dihydroxyacetone & - & - \\
\hline $\mathrm{pH}$ in Voges-Proskauer broth & $<6.0$ & $4 \cdot 9-5 \cdot 5$ \\
\hline \multicolumn{3}{|l|}{ Decomposition of: } \\
\hline Tyrosine & - & + \\
\hline Thiamine & NT & + \\
\hline \multicolumn{3}{|l|}{ Hydrolysis of: } \\
\hline Casein & + & + \\
\hline Starch & + & + \\
\hline Urea & + & - \\
\hline Tween 80 & - & - \\
\hline Egg yolk lecithin & Weak & - \\
\hline \multicolumn{3}{|l|}{ Utilization of: } \\
\hline Citrate & - & + \\
\hline Succinate & + & + \\
\hline Acetate & + & + \\
\hline Fumarate & + & + \\
\hline L-Malate & + & + \\
\hline Litmus milk & + & No change \\
\hline Optimum growth temperature $\left({ }^{\circ} \mathrm{C}\right)$ & 37 & 28 \\
\hline Growth at pH 5.6 & + & - \\
\hline \multicolumn{3}{|l|}{ Growth in the presence of: } \\
\hline $0.001 \%$ lysozyme & NT & - \\
\hline $5 \% \mathrm{NaCl}$ & + & $\mathrm{v}$ \\
\hline \multicolumn{3}{|l|}{ Fermentation of: } \\
\hline D-Glucose & + & + \\
\hline L-Arabinose & - & $\mathrm{v}$ \\
\hline Mannitol & - & $\mathrm{v}$ \\
\hline D-Xylose & - & - \\
\hline $\mathrm{G}+\mathrm{C}$ content $(\mathrm{mol} \%)$ & 55 & $52-54$ \\
\hline
\end{tabular}

One feature of several members of the genus Paenibacillus is that they produce extracellular polysaccharide-degrading enzymes (Shida et al., 1997a; Nakamura, 1987; Alexander \& Priest, 1989; Claus \& Berkeley, 1986; Priest et al., 1988). Some of these strains, such as $P$. kobensis IFO 15729, Paenibacillus glucanolyticus DSMZ 5162 ${ }^{\mathrm{T}}$, Paenibacillus lautus NRRL NRS- $666^{\mathrm{T}}$ and $P$. curdlanolyticus IFO $15724^{\mathrm{T}}$, are located quite close to morphotype $\mathrm{T} 168^{\mathrm{T}}$ on the phylogenetic tree. Experiments are currently in progress in this laboratory to determine whether any of the other members of the Paenibacillus cluster exhibit morphotype pattern-forming characteristics and, if so, whether this behaviour can be studied using the generic models developed previously (Ben-Jacob, 1997; BenJacob et al., 1998a, b; Gutnick \& Ben-Jacob, 1998).

Preliminary results in this regard have demonstrated that at least nine different species of Bacillus and two different species of Paenibacillus fail to form patterns under the conditions described here (M. Tcherpakov, unpublished results). The two Paenibacillus species, $P$. 
Table 3. Cellular fatty acid composition of $\mathrm{T}^{168^{\top}}$ and several species of the genera Paenibacillus and Bacillus

The percentage of the total cellular fatty acid content is shown. Data for fatty acid composition of strains of Bacillus and Paenibacillus were taken from Shida et al. (1997a). Data for fatty acid composition of the T morphotype was obtained as described in Methods. ND, Not detected.

\begin{tabular}{|c|c|c|c|c|c|c|c|c|c|c|}
\hline \multirow[t]{3}{*}{ Species and strain } & \multicolumn{8}{|c|}{ Saturated acids } & \multicolumn{2}{|c|}{ Unsaturated acids } \\
\hline & \multicolumn{3}{|c|}{ Straight-chain } & \multicolumn{3}{|c|}{ Iso-branched } & \multicolumn{2}{|c|}{ Anteiso-branched } & \multirow{2}{*}{$\mathrm{C}_{16: 1} \omega 11$} & \multirow[t]{2}{*}{ Iso- $C_{17: 1} \omega 10$} \\
\hline & $\mathrm{C}_{14: 0}$ & $\mathrm{C}_{15: 0}$ & $\mathrm{C}_{16: 0}$ & $\mathrm{C}_{15: 0}$ & $\mathrm{C}_{16: 0}$ & $\mathrm{C}_{17: 0}$ & $\mathrm{C}_{15: 0}$ & $\mathrm{C}_{17: 0}$ & & \\
\hline Morphotype T168 & $0 \cdot 7$ & $3 \cdot 3$ & $6 \cdot 3$ & $6 \cdot 0$ & $4 \cdot 6$ & $7 \cdot 5$ & $43 \cdot 2$ & $20 \cdot 6$ & $2 \cdot 7$ & $1 \cdot 4$ \\
\hline \multicolumn{11}{|l|}{ Paenibacillus thiaminolyticus } \\
\hline $\mathrm{JCM} 8360^{\mathrm{T}}$ & $0 \cdot 9$ & 0.6 & $10 \cdot 5$ & $10 \cdot 5$ & $5 \cdot 8$ & $6 \cdot 5$ & $42 \cdot 4$ & $11 \cdot 6$ & $5 \cdot 2$ & $1 \cdot 7$ \\
\hline JCM 7540 & $0 \cdot 5$ & $0 \cdot 5$ & $8 \cdot 5$ & $10 \cdot 7$ & $6 \cdot 3$ & $7 \cdot 1$ & $45 \cdot 3$ & $16 \cdot 4$ & $1 \cdot 3$ & $1 \cdot 0$ \\
\hline \multicolumn{11}{|l|}{ Paenibacillus alvei } \\
\hline IFO $3343^{\mathrm{T}}$ & $2 \cdot 3$ & $1 \cdot 6$ & $15 \cdot 3$ & $12 \cdot 3$ & $2 \cdot 3$ & $3 \cdot 3$ & $53 \cdot 9$ & $3 \cdot 3$ & $1 \cdot 3$ & $0 \cdot 5$ \\
\hline NRRL NRS-811 & $1 \cdot 8$ & $2 \cdot 0$ & $12 \cdot 2$ & $9 \cdot 2$ & $2 \cdot 5$ & $2 \cdot 0$ & $60 \cdot 3$ & $4 \cdot 0$ & $0 \cdot 8$ & $0 \cdot 2$ \\
\hline \multicolumn{11}{|l|}{ Paenibacillus kobensis } \\
\hline IFO $15729^{\mathrm{T}}$ & $1 \cdot 0$ & $2 \cdot 8$ & $12 \cdot 2$ & $2 \cdot 0$ & $8 \cdot 8$ & $0 \cdot 5$ & $65 \cdot 7$ & $3 \cdot 2$ & ND & ND \\
\hline IFO 15730 & 0.7 & $2 \cdot 7$ & $8 \cdot 3$ & $1 \cdot 7$ & $16 \cdot 2$ & $0 \cdot 7$ & $61 \cdot 1$ & $4 \cdot 1$ & ND & ND \\
\hline \multicolumn{11}{|l|}{ Paenibacillus apiarius } \\
\hline NRRL NRS- $1438^{\mathrm{T}}$ & $0 \cdot 6$ & $2 \cdot 2$ & $4 \cdot 8$ & $8 \cdot 3$ & $4 \cdot 2$ & $5 \cdot 5$ & $60 \cdot 5$ & $16 \cdot 3$ & $0 \cdot 8$ & $0 \cdot 2$ \\
\hline NRRL NRS-1578 & $0 \cdot 5$ & $1 \cdot 4$ & $4 \cdot 6$ & $6 \cdot 1$ & $5 \cdot 3$ & $6 \cdot 0$ & $59 \cdot 3$ & $16 \cdot 3$ & $0 \cdot 2$ & $0 \cdot 3$ \\
\hline \multicolumn{11}{|l|}{ Paenibacillus larvae subsp. pulvifaciens } \\
\hline IFO $15408^{\mathrm{T}}$ & $0 \cdot 6$ & $1 \cdot 3$ & $6 \cdot 4$ & $9 \cdot 5$ & $5 \cdot 3$ & $4 \cdot 5$ & $48 \cdot 8$ & $20 \cdot 7$ & $0 \cdot 8$ & ND \\
\hline NRRL B-14152 & $0 \cdot 2$ & $1 \cdot 6$ & $4 \cdot 7$ & $8 \cdot 0$ & $1 \cdot 3$ & $7 \cdot 2$ & $40 \cdot 8$ & $30 \cdot 2$ & $1 \cdot 0$ & ND \\
\hline Bacillus subtilis JCM $1465^{\mathrm{T}}$ & $0 \cdot 3$ & $2 \cdot 3$ & $1 \cdot 3$ & $28 \cdot 4$ & $2 \cdot 0$ & $6 \cdot 1$ & $44 \cdot 5$ & $6 \cdot 8$ & ND & $0 \cdot 5$ \\
\hline Bacillus cereus $\mathrm{JCM} 2152^{\mathrm{T}}$ & $3 \cdot 1$ & 4.9 & $2 \cdot 4$ & $48 \cdot 7$ & $2 \cdot 7$ & $6 \cdot 2$ & $3 \cdot 8$ & 0.7 & $4 \cdot 4$ & $2 \cdot 8$ \\
\hline Bacillus stearothermophilus JCM $2501^{\mathrm{T}}$ & ND & ND & $3 \cdot 4$ & $27 \cdot 5$ & $5 \cdot 6$ & $17 \cdot 2$ & $7 \cdot 8$ & $38 \cdot 6$ & ND & ND \\
\hline Bacillus sphaericus JCM $2502^{\mathrm{T}}$ & $1 \cdot 4$ & $6 \cdot 8$ & $1 \cdot 3$ & $53 \cdot 4$ & $6 \cdot 9$ & $2 \cdot 1$ & $8 \cdot 8$ & 0.9 & ND & ND \\
\hline
\end{tabular}

alvei IFO $3343^{\mathrm{T}}$ and P. apiarius NRRL NRS-1578, that showed no pattern-forming characteristics are quite closely linked to the $\mathrm{T}$ morphotype on the phylogenetic tree.

\section{Description of Paenibacillus dendritiformis sp. nov.}

Paenibacillus dendritiformis (den.dri.ti.for'mis. G. n. dendron tree; M.L. adj. formis shaped).

Rod-shaped $0 \cdot 5-1 \cdot 0 \mu \mathrm{m}$ by $2 \cdot 0-3 \cdot 0 \mu \mathrm{m}$ ( $\mathrm{T}$ morphotype) or $1.0-1.5 \mu \mathrm{m}$ by $4.0-6.0 \mu \mathrm{m}$ (C morphotype). Gram-negative. Motile. Round, cylindrical or oval spores formed in swelling sporangia. On $2.0 \%$ agar plates containing $0.5 \%$ yeast extract, $1.0 \%$ bactotryptone and $1.0 \% \mathrm{NaCl}$, colonies are non-pigmented, translucent, thin, smooth, regular, entire and 1.0 $2.0 \mathrm{~mm}$ in diameter. Catalase and oxidase are produced. Facultatively anaerobic. Acetylmethylcarbinol is not produced. Indole is produced. The $\mathrm{pH}$ in Voges-Proskauer broth (test for acetylmethylcarbinol production) is less than $6 \cdot 0$. Nitrate is not reduced to nitrite. Starch and casein are hydrolysed. Urea is decomposed. Egg yolk lecithin is weakly decomposed. Tween 80 is not decomposed. There is no degradation of tyrosine. Acetate, fumarate, malate and succinate are utilized. Citrate is not utilized. Growth occurs at
pH 5.6 or 5.7 . There is change in litmus milk in $7 \mathrm{~d}$. Grows in the presence of $5 \% \mathrm{NaCl}$. Optimal growth temperature is $37^{\circ} \mathrm{C}$; weak growth at $20^{\circ} \mathrm{C}$; maximum growth temperature is $45^{\circ} \mathrm{C}$. Acid but no gas is produced from cellobiose, glucose, mannose, sucrose and trehalose. No acid is produced from arabinose, fructose, lactose, mannitol or xylose. The $\mathrm{G}+\mathrm{C}$ content is $55 \mathrm{~mol} \%$. Isolated occasionally from cultures of Bacillus subtilis 168. The ability to form complex symmetrical tip-splitting (T) or chiral (C) patterns on thin agar plates containing between 0.7 and $1.75 \%$ agar is a characteristic of this species. Morphotype transition from $\mathrm{T}$ to $\mathrm{C}$ is generally observed on thin agar plates containing up to $1.2 \%$ agar, while reverse transitions from $\mathrm{C}$ to $\mathrm{T}$ are observed on agar plates containing at least $1.5 \%$ agar. Such transitions generally require a period of about $48 \mathrm{~h}$ at $30{ }^{\circ} \mathrm{C}$.

Isolate $\mathrm{T} 168^{\mathrm{T}}$ was deposited as the type strain in the Bacillus Genetic Stock Center, Columbus, OH, USA, as strain $30 \mathrm{~A} 1^{\mathrm{T}}$.

\section{ACKNOWLEDGEMENTS}

We thank Professor Dan Graur for his help in choosing the name of the species and Dimitry Govorko for help with the 
CLUSTAL program. We acknowledge the excellent technical assistance of Rina Avigad and Inna Brainis. Thanks are also extended to Inon Cohen for his outstanding contributions to the early development of morphotype characterization and modelling. This work was supported by grant no. 95-00410 from the US-Israel Binational Science Foundation and grant no. 593-95 from the Israel Science Foundation.

\section{REFERENCES}

Alexander, B. \& Priest, F. G. (1989). Bacillus glucanolyticus, a new species that degrades a variety of $\beta$-glucans. Int $J$ Syst Bacteriol 39, 112-115.

Ash, C., Farrow, J. A. E., Wallbanks, S. \& Collins, M. D. (1991). Phylogenetic heterogeneity of the genus Bacillus revealed by comparative analysis of small subunit ribosomal RNA sequences. Lett Appl Microbiol 13, 202-206.

Ash, C., Priest, F. G. \& Collins, M. D. (1993). Molecular identification of rRNA group 3 bacilli (Ash, Farrow, Wallbanks, and Collins) using a PCR probe test. Proposal for the creation of a new genus Paenibacillus. Antonie Leeuwenhoek 64, 253-260.

Ben-Jacob, E. (1997). From snowflake formation to growth of bacterial colonies. Part II. Cooperative formation of colonial patterns. Contemp Phys 38, 205-241.

Ben-Jacob, E. \& Garik, P. (1990). The formation of patterns in non-equilibrium growth. Nature 343, 523-530.

Ben-Jacob, E., Shmueli, H., Shochet, O. \& Tenenbaum, A. (1992). Adaptive self-organization during growth of bacterial colonies. Physica A 187, 378-424.

Ben-Jacob, E., Shochet, O., Tenenbaum, A., Cohen, I., Czirok, A. \& Vicsek, T. (1994). Generic modelling of cooperative growth patterns in bacterial colonies. Nature 368, 4649.

Ben-Jacob, E., Cohen, I., Shochet, O., Czirok, A. \& Vicsek, T. (1995). Cooperative formation of chiral patterns during growth of bacterial colonies. Phys Rev Lett 75, 2899-2902.

Ben-Jacob, E., Cohen, I., Czirok, A., Vicsek, T. \& Gutnick, D. L. (1997). Chemomodulation of cellular movement, collective formation of vortices by swarming bacteria, and colonial development. Physica A 238, 181-197.

Ben-Jacob, E., Cohen, I. \& Gutnick, D. L. (1998a). Cooperative organization of bacterial colonies: from genotype to morphotype. Annu Rev Microbiol 52, 779-806.

Ben-Jacob, E., Cohen, I. \& Gutnick, D. L. (1998b). Chemotaxisbased self-organization during colonial morphogenesis. Comments Mol Cell Biophys (in press).

Claus, D. \& Berkeley, R. C. W. (1986). Genus Bacillus Cohn 1872. In Bergey's Manual of Systematic Bacteriology, vol. 2, pp. 1105-1140. Edited by P. H. A. Sneath, N. S. Mair, M. E. Sharpe \& J. G. Holt. Baltimore: Williams \& Wilkins.

Di Cello, F., Pepi, M., Baldi, F. \& Fani, R. (1997). Molecular characterization of an n-alkane-degrading bacterial community and identification of a new species, Acinetobacter venetianus. Res Microbiol 148, 237-249.

Edwards, P. R. \& Ewing, W. H. (1972). Identification of Enterobacteriaceae. Minneapolis: Burgess.

Fox, G. E. \& Rossler, D. (1991). Phylogenetic diversity in the genus Bacillus as seen by $16 \mathrm{~S}$ RNA sequencing studies. Syst Appl Microbiol 14, 266-269.

Fujikawa, H. \& Matsushita, M. (1989). Fractal growth of Bacillus subtilis on agar plates. J Phys Soc Jpn 58, 3875-3878.

Gordon, R. E., Haynes, W. C. \& Pang, C. H. (1973). The Genus
Bacillus. Agriculture Handbook no. 427. Washington, DC: US Department of Agriculture.

Gutnick, D. L. \& Ben-Jacob, E. (1998). Complex pattern formation and cooperative organization of bacterial colonies. In Microbial Ecology and Infectious Diseases. Edited by E. Rosenberg. Washington, DC: American Society for Microbiology (in press).

Heyndrickx, M., Vandemeulebroecke, K., Scheldeman, P. and 7 other authors (1995). Paenibacillus (formerly Bacillus) gordonae (Pichinoty et al. 1986) Ash et al. 1994 is a later subjective synonym of Paenibacillus (formerly Bacillus) validus (Nakamura 1984) Ash et al. 1994: emended description of $P$. validus. Int J Syst Bacteriol 45, 661-669.

Heyndrickx, M., Vandemeulebroecke, K., Hoste, B., Janssen, P., Kersters, K., De Vos, P., Logan, N. A., Ali, N. \& Berkeley, R. C. W. (1996a). Reclassification of Paenibacillus (formerly Bacillus) pulvifaciens (Nakamura 1984) Ash et al. 1994, a later subjective synonym of Paenibacillus (formerly Bacillus) larvae (White 1906) Ash et al. 1994, as a subspecies of $P$. larvae, with emended descriptions of $P$. larvae as $P$. larvae subsp. larvae and $P$. larvae subsp. pulvifaciens. Int J Syst Bacteriol 46, 270-279.

Heyndrickx, M., Vandemeulebroecke, K., Scheldeman, P., Kersters, K., De Vos, P., Logan, N. A., Aziz, A. M., Ali, N. \& Berkeley, R. C. W. (1996b). A polyphasic reassessment of the genus Paenibacillus, reclassification of Bacillus lautus (Nakamura 1984) as Paenibacillus lautus comb. nov. and of Bacillus peoriae (Montefusco et al. 1993) as Paenibacillus peoriae comb. nov., and emended descriptions of $P$. lautus and of $P$. peoriae. Int J Syst Bacteriol 46, 988-1003.

Kanzawa, Y., Harada, A., Takeuchi, M., Yokota, A. \& Harada, T. (1995). Bacillus curdlanolyticus sp. nov. and Bacillus kobensis sp. nov., which hydrolyse resistant curdlan. Int J Syst Bacteriol 45, 515-521.

Matsushita, M. \& Fujikawa, H. (1990). Diffusion-limited growth in bacterial colony formation. Physica A 168, 498-506.

Matsushita, M., Wakita, J.-I. \& Matsuyama, T. (1995). Growth and morphological changes of bacterial colonies. In SpatioTemporal Patterns in Nonequilibrium Complex Systems, pp. 609-618. Santa-Fe Institute Studies in the Sciences of Complexity. Edited by P. E. Cladis \& P. Palffy-Muhoray. New York: Addison-Weseley.

Matsuyama, T. \& Matsushita, M. (1993). Fractal morphogenesis by a bacterial cell population. Crit Rev Microbiol 19, 117-135.

Matsuyama, T., Harshey, R. M. \& Matsushita, M. (1993). Selfsimilar colony morphogenesis by bacteria as the experimental model of fractal growth by a cell population. Fractals 1, 302-311.

Nakamura, L. K. (1987). Bacillus alginolyticus sp. nov. and Bacillus chondroitinus sp. nov., two alginate-degrading species Int J Syst Bacteriol 37, 284-286.

Nakamura, L. K. (1990). Bacillus thiaminolyticus sp. nov., nom rev. Int J Syst Bacteriol 40, 242-246.

Nakamura, L. K. (1996). Paenibacillus apiarius sp. nov. Int J Syst Bacteriol 46, 688-693.

Nielsen, P., Rainey, F. A., Outtrup, H., Priest, F. G. \& Fritze, D. (1994). Comparative $16 \mathrm{~S}$ rDNA sequence analysis of some alkaliphilic bacilli and the establishment of a sixth rRNA group within the genus Bacillus. FEMS Microbiol Lett 117, 61-66.

Priest, F. G., Goodfellow, M. \& Todd, C. (1988). A numerical classification of the genus Bacillus. $J$ Gen Microbiol 134, 1847-1882.

Rainey, F. A., Fritze, D. \& Stackebrandt, E. (1994). The phylo- 
genetic diversity of thermophilic members of the genus Bacillus as revealed by $16 \mathrm{~S}$ rDNA analysis. FEMS Microbiol Lett 115 , 205-211.

Rudner, R., Martsinkevich, O., Leung, W. \& Jarvis, E. D. (1998). Classification and genetic characterization of pattern-forming bacilli. Mol Microbiol 27, 687-703.

Sambrook, J., Fritsch, E. F. \& Maniatis, T. (1989). Molecular Cloning : a Laboratory Manual, 2nd edn. Cold Spring Harbor, NY: Cold Spring Harbor Laboratory.

Shida, O., Takagi, H., Kadowaki, K., Nakamura, L. K. \& Komagata, K. (1997a). Transfer of Bacillus alginolyticus, Bacillus chondroitinus, Bacillus curdlanolyticus, Bacillus glucanolyticus, Bacillus kobensis, and Bacillus thiaminolyticus to the genus Paenibacillus and emended description of the genus Paenibacillus. Int J Syst Bacteriol 47, 289-298.

Shida, O., Takagi, H., Kadowaki, K., Nakamura, L. K. \& Komagata, K. (1997b). Emended description of Paenibacillus amylolyticus and description of Paenibacillus illinoisensis sp. nov. and Paenibacillus chibensis sp. nov. Int J Syst Bacteriol 47, 299-306.

Steel, K. J. (1961). The oxidase reaction as a taxonomic tool. $J$ Gen Microbiol 25, 297-306.

Suzuki, T. \& Yamasato, K. (1994). Phylogeny of spore-forming lactic acid bacteria based on 16S rRNA gene sequence. FEMS Microbiol Lett 115, 13-17. 